\title{
Anterior release posterior internal distraction and subsequent posterior spinal fusion for the treatment of severe kyphoscoliosis
}

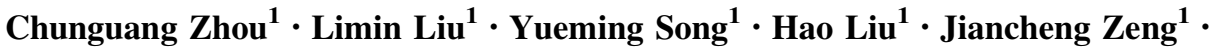 \\ Xi Yang ${ }^{1}$
}

Received: 1 December 2014/Revised: 19 March 2015/Accepted: 19 March 2015/Published online: 27 March 2015

(C) Springer-Verlag Berlin Heidelberg 2015

\begin{abstract}
Purpose To evaluate the outcome and complications of anterior release, posterior internal distraction and subsequent posterior spinal fusion for the treatment of severe kyphoscoliosis.

Methods The medical records and spinal imaging of 17 consecutive severe kyphoscoliosis patients who underwent anterior release, posterior internal distraction and subsequent posterior spinal fusion were reviewed.

Results Patients underwent spinal deformity correction at the mean age of $22.6 \pm 8.4$ years (range 15-44 years) with mean follow-up of $37.4 \pm 12.0$ months (range 24-60 months). The preoperative thoracic kyphosis of $83.5^{\circ} \pm 16.3^{\circ}$ (range $60^{\circ}-$ $115^{\circ}$ ) was corrected to $37.5^{\circ} \pm 7.9^{\circ}$ (range $20^{\circ}-49^{\circ}$ ) at the final follow-up. The preoperative major curve of $110.1^{\circ} \pm$ $16.8^{\circ}$ (range $92^{\circ}-145^{\circ}$ ) was corrected to $33.5^{\circ} \pm 13.9^{\circ}$ (range $12^{\circ}-63^{\circ}$ ) at the final follow-up, with a scoliosis correction of $70.3 \%$. At the most recent follow-up, the correction rate of proximal thoracic curve and thoracolumbar or lumbar curve was 57.1 and $74.8 \%$, respectively. Transient dyspnoea occurred in one patient after the initial surgery and subsequently resolved. No ventilator support was needed. Three patients complained the pain of concave soft tissue after the first distraction. There were no neurological complications or any deep wound infections. No complication of instrumentation was found at final follow-up.
\end{abstract}

Limin Liu

huaxicoa@163.com

1 Department of Orthopedics, West China Hospital of Sichuan University, Chengdu, Sichuan 610041 ,

People's Republic of China
Conclusions In the treatment of severe kyphoscoliosis, anterior release, posterior internal distraction and subsequent posterior spinal fusion, which obviates three-column osteotomy, is a good alternative correction method.

Keywords Anterior release · Internal distraction - Spinal fusion $\cdot$ Severe kyphoscoliosis

\section{Introduction}

Severe kyphoscoliosis frequently results in early truncal decompensation and a large compensatory curve, which may progress with time. The correction of severe scoliosis is accompanied by high risk of neurologic compromise, especially if there is a significant kyphotic component; so the correction of severe kyphoscoliosis is a great challenge for spine surgeon. Current surgical strategies include aggressive anterior and posterior column osteotomies, either with a front-back [1-5] or a posterior-only approach [620]. Although with satisfactory correction of deformity, such kind of osteotomies is accompanied by high risk of complications [1-20].

We have introduced and published our preliminary experience with staged anterior release, posterior internal distraction and subsequent posterior spinal fusion in severe and rigid scoliosis [21]. With this method, we achieved a scoliosis correction of $74.3 \%$, and the preoperative thoracic kyphosis of $62.3^{\circ}$ was corrected to $33.8^{\circ}$ at the last follow-up. Eight of 15 patients in that study had preoperative thoracic kyphosis greater than $60^{\circ}$. Without performing VCR, all eight patients with kyphoscoliosis achieved satisfactory correction of both scoliosis and kyphosis. After that, more patients with severe kyphoscoliosis were treated by this method. The purpose of 
this study was to examine the indications, correction rates, and complications of staged anterior release, posterior internal distraction and subsequent posterior spinal fusion for the treatment of severe kyphoscoliosis at a single center.

\section{Materials and methods}

In this study, 17 patients with severe kyphoscoliosis (11 idiopathic, 6 syringomyelia-associated scoliosis) underwent surgery between 2009 and 2012 by a single spine surgeon (L.L.M.). Inclusion criteria were curves with Cobb angles of at least $90^{\circ}$, a flexibility of less than $30 \%$ on bending films, and thoracic kyphosis greater than $60^{\circ}$. There were 6 males and 11 females with an average age of $22.6 \pm 8.4$ years (range 15-44 years). They were all thoracic curves (Table 1). Average preoperative Cobb angle in coronal plane was $110.1^{\circ} \pm 16.8^{\circ}$ (range $92^{\circ}-145^{\circ}$ ) with flexibility of $10.8 \%$ on bending radiograms (Fig. 1a). Average preoperative thoracic kyphosis was $83.5^{\circ} \pm 16.3^{\circ}$ (range $60^{\circ}-115^{\circ}$ ).

All patients underwent staged anterior release, posterior internal distraction and subsequent posterior spinal fusion. Intraoperative spinal cord monitoring was performed in all patients. Preoperative magnetic resonance imaging was obtained to rule out any neural axis abnormalities that would contraindicate internal distraction. Syringomyelia was found in six patients and one patient with the dimension of syringomyelia more than $50 \%$ of the cord diameter underwent subarachnoid space shunt before the correction of kyphoscoliosis.

The clinical records were reviewed for demographic data, operating time, average blood loss, and complications. All patients were reviewed after a minimum followup of 2 years. No patient was lost to follow-up. To monitor the correction of the deformity, posteroanterior and lateral radiographs were made preoperatively, after distraction, after arthrodesis, and at the time of the last follow-up (Fig. 1a-e). Radiographic analysis, which included Cobb angle of coronal curves, coronal balance, sagittal balance, thoracic kyphosis and lumbar lordosis, was performed on these series radiographs. Coronal balance was measured as the distance between the $\mathrm{C} 7$ plumb line and the center sacral line. Sagittal balance was measured as the distance between $\mathrm{C} 7$ plumb line and the posterior superior corner of S1. Thoracic kyphosis was measured by the Cobb method from the superior endplate of $\mathrm{T} 5$ to the lower endplate of $\mathrm{T} 12$, and lumbar lordosis from the superior endplate of $\mathrm{T} 12$ to the endplate of S1.

\section{Surgical techniques}

Anterior release consisted of an approach on the convex side of the area to be resected through a thoracic incision. The rib conforming to the uppermost level of the spine to be approached was exposed and removed. The intervertebral discs were fully excised back to the posterior

Table 1 Data on the patients

\begin{tabular}{|c|c|c|c|c|c|c|c|}
\hline Patient no. & Age (years) & Sex & Diagnosis & Level (apex) & Anterior release length & Posterior fusion length & Follow-up (months) \\
\hline 1 & 20 & $\mathrm{~F}$ & IS & $\mathrm{T}$ & T6-T11 & T2-L2 & 60 \\
\hline 2 & 17 & $\mathrm{~F}$ & IS & $\mathrm{T}$ & T6-T10 & $\mathrm{T} 2-\mathrm{L} 4$ & 58 \\
\hline 3 & 15 & $\mathrm{~F}$ & IS & $\mathrm{T}$ & T6-T10 & $\mathrm{T} 2-\mathrm{L} 3$ & 56 \\
\hline 4 & 18 & M & IS & $\mathrm{T}$ & $\mathrm{T} 7-\mathrm{T} 11$ & $\mathrm{~T} 2-\mathrm{L} 4$ & 48 \\
\hline 5 & 21 & M & SAS & $\mathrm{T}$ & $\mathrm{T} 7-\mathrm{T} 11$ & T3-L4 & 36 \\
\hline 6 & 20 & M & SAS & $\mathrm{T}$ & $\mathrm{T} 7-\mathrm{T} 11$ & $\mathrm{~T} 2-\mathrm{L} 3$ & 48 \\
\hline 7 & 23 & $\mathrm{~F}$ & IS & $\mathrm{T}$ & $\mathrm{T} 7-\mathrm{T} 11$ & T3-L4 & 36 \\
\hline 8 & 17 & M & IS & $\mathrm{T}$ & $\mathrm{T} 7-\mathrm{T} 11$ & $\mathrm{~T} 2-\mathrm{L} 2$ & 36 \\
\hline 9 & 15 & M & SAS & $\mathrm{T}$ & $\mathrm{T} 8-\mathrm{T} 12$ & $\mathrm{~T} 2-\mathrm{L} 3$ & 30 \\
\hline 10 & 23 & $\mathrm{~F}$ & SAS & $\mathrm{T}$ & $\mathrm{T} 7-\mathrm{T} 11$ & T2-L3 & 32 \\
\hline 11 & 44 & M & SAS & $\mathrm{T}$ & $\mathrm{T} 7-\mathrm{T} 11$ & T4-L4 & 28 \\
\hline 12 & 24 & $\mathrm{~F}$ & IS & $\mathrm{T}$ & $\mathrm{T} 7-\mathrm{T} 11$ & T2-L2 & 36 \\
\hline 13 & 15 & $\mathrm{~F}$ & IS & $\mathrm{T}$ & $\mathrm{T} 7-\mathrm{T} 11$ & T2-L4 & 30 \\
\hline 14 & 22 & $\mathrm{~F}$ & SAS & $\mathrm{T}$ & $\mathrm{T} 8-\mathrm{T} 12$ & T2-L4 & 28 \\
\hline 15 & 24 & $\mathrm{~F}$ & IS & $\mathrm{T}$ & $\mathrm{T} 7-\mathrm{T} 11$ & T2-L4 & 24 \\
\hline 16 & 25 & $\mathrm{~F}$ & IS & $\mathrm{T}$ & T6-T10 & T2-L3 & 26 \\
\hline 17 & 42 & $\mathrm{~F}$ & IS & $\mathrm{T}$ & T7-T11 & T2-L4 & 24 \\
\hline
\end{tabular}

$I S$ idiopathic scoliosis, $S A S$ syringomyelia-associated scoliosis, $T$ thoracic 
Fig. 1 The patient was a

23-year-old female with severe idiopathic scoliosis. a She had a $118^{\circ}$ coronal plane deformity and $90^{\circ}$ of thoracic kyphosis. Side-bending radiographs demonstrated $11.0 \%$ flexibility. b She underwent an anterior release (T7-T8, T8-T9, T9T10, T10-T11 discs) and initial distraction. The major curve was corrected to $77^{\circ}$, and thoracic kyphosis was corrected to $57^{\circ}$. c After second distraction, the major curve was corrected to $74^{\circ}$, and thoracic kyphosis increased to $54^{\circ}$. d After posterior spinal fusion from $\mathrm{T} 2$ to $\mathrm{L} 3$, the major curves were corrected to $58^{\circ}$, and thoracic kyphosis was corrected to $45^{\circ}$. e Anteroposterior and lateral radiographs taken 3 years after surgery. The major curve was $58^{\circ}$, and thoracic kyphosis was $48^{\circ}$. f Pre- and postoperative clinical photographs showed the marked clinical correction

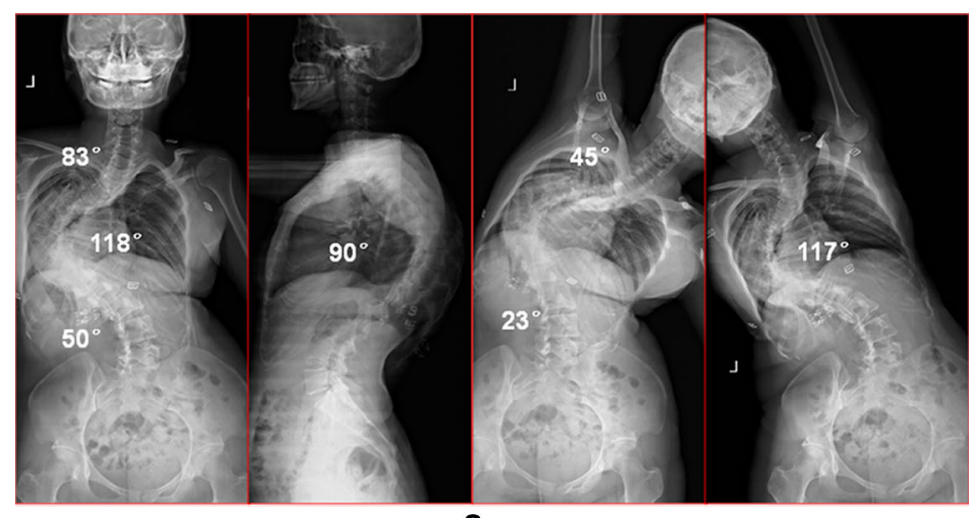

a

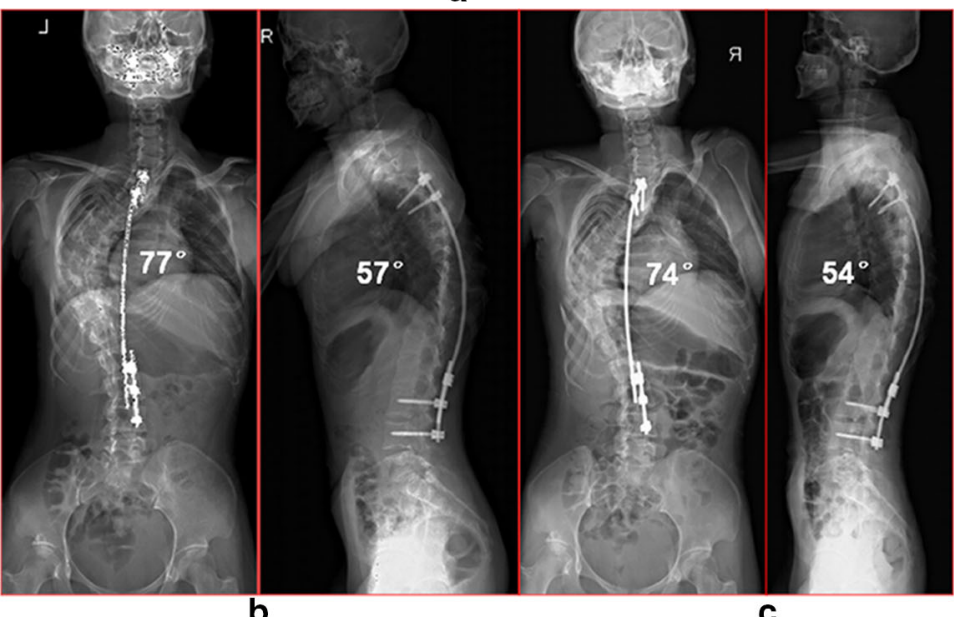

C
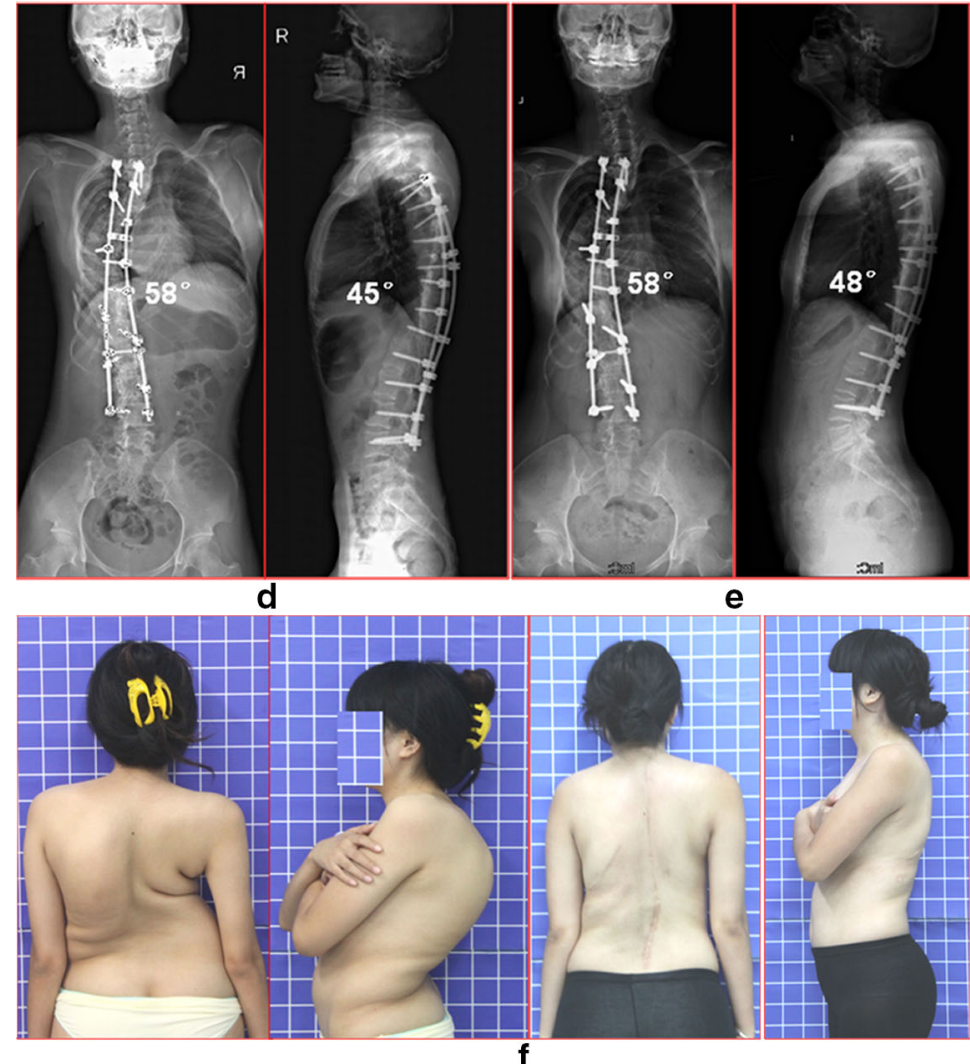
longitudinal ligament. Great care was taken to remove as much discs as possible to provide adequate anterior release. In addition, rib heads were removed to increase the flexibility of spine. The vertebral mobility is verified by rotating a Cobb elevator in the disc space. After pleural closure, the chest cavity was irrigated, and a chest tube was placed under direct vision.

After the anterior release, the patient was turned over to the prone position to receive posterior internal distraction. Two small incisions were performed to expose the cephalad and caudad vertebra that would be fixed. At least two points of fixation at the cephalad end and two at the caudad end were used to achieve adequate fixation. One longer distraction rod connected to the cephalad fixation points was inserted subcutaneously, and another shorter distraction rod was connected to the caudad fixation points. Two rods were connected by Domino Connector (Medtronic, Fort Worth, TX). The pedicle screw caps were locked. After the screw caps on medial side of Domino Connector were locked, the distraction maneuver was performed between distal pedicle screw and Domino Connector. Then the screw caps on lateral side of Domino Connector were locked, and the screw caps on medial side of Domino Connector were loosened. Similar distraction maneuver was performed between Domino Connector and rod holder. The distraction maneuver was performed under spinal cord monitoring in all patients, and both somatosensory evoked potentials and motor evoked potentials were observed throughout each procedure. To take advantage of the viscoelastic nature of the spine and to maximize correction with minimal stress, we allowed a few minutes for stress relaxation between multiple episodes of distraction during each distraction procedure [22].

In some patients, an additional distraction procedure was performed 1-2 weeks after the initial surgery. Similar to Buchowski's experience, we based the decision on the perceived curve stiffness and rigidity and on the response of the curve to distraction. If the curve did not correct by approximately $50 \%$ or larger than $50^{\circ}$ after the first distraction procedure, we were more likely to perform a second distraction [22].

One to seven weeks after the initial surgery or second distraction, definitive posterior spinal fusion was performed. Pedicle screws were inserted segmentally, and Ponte osteotomy was performed on several segments adjacent to the apex to provide adequate release. Then a rod contoured to the shape of the deformity was applied on the convex side, and rod derotation, compression and distraction were performed on the convex side to correct the deformity. The temporary internal distraction rod on the concave side was removed. Another permanent rod was applied on the concave side, and similar correction manipulation was performed. Decortication was done to all levels of planned fusion and bone graft was placed along the spine for posterior fusion.

After the first surgery, nurses instructed patients to cough and breathe deeply to promote optimal pulmonary function. Chest tubes are discontinued when drainage is less than $80 \mathrm{ml}$ per 8 -h shift. Patient-controlled analgesic pumps were ordered to ensure optimal pain control. Nurses used strict sterile technique while performing postoperative dressing changes to diminish the likelihood of surgical wound infections. Before the final fusion surgery, patients stayed in bed, and flexion, extension and twist were restricted. In the first 3 days, patients turned over under the assistance of nurses, after that, they did by themselves. Exercises for extremities were encouraged. The patients were allowed to sit up in bed $48 \mathrm{~h}$ after final fusion surgery. Two weeks after surgery, the patients were allowed to ambulate in a custom-made thoracolumbosacral orthosis. The orthosis was kept for 6 months and removed if radiograph after 6 months did not show any sign of pseudarthrosis.

\section{Results}

Nine patients underwent two distraction procedures before the final fusion, and the remaining eight patients underwent only one distraction, for a total of 26 intraoperative distraction procedures. In nine patients who underwent two distraction procedures, the interval between two distraction procedures averaged $11.6 \pm 2.2$ days (range 8-14 days), and the mean time between the second distraction and final procedure was $31.2 \pm 11.9$ days (range 8-52 days). In eight patients who underwent only one distraction, the interval between the distraction and final procedures averaged $19.3 \pm 10.6$ days (range 13-40 days). The average number of anteriorly removed discs was $4.1 \pm 0.2$ (range 4-5). Average posterior fusion length was $14.1 \pm 0.8$ vertebrae (range 13-15, Table 1).

The preoperative thoracic kyphosis of $83.5^{\circ} \pm 16.3^{\circ}$ (range $60^{\circ}-115^{\circ}$ ) was corrected to $46.9^{\circ} \pm 10.7^{\circ}$ (range $21^{\circ}-65^{\circ}$ ) after the first internal distraction, and in nine patients who underwent two distraction procedures, the second distraction increased the thoracic kyphosis from $47.2^{\circ} \pm 13.7^{\circ}\left(\right.$ range $21^{\circ}-65^{\circ}$ ) to $49^{\circ} \pm 15.5^{\circ}$ (range $29^{\circ}$ $\left.70^{\circ}\right)$. After the definitive spinal fusion, the thoracic kyphosis averaged $37.3^{\circ} \pm 9.6^{\circ}$ (range $22^{\circ}-64^{\circ}$ ), and it averaged $37.5^{\circ} \pm 7.9^{\circ}$ (range $20^{\circ}-49^{\circ}$ ) at the final followup (Table 2; Fig. 1a-f). The preoperative lumbar lordosis of $-69.6^{\circ} \pm 17.8^{\circ}$ (range $-102^{\circ}$ to $-39^{\circ}$ ) was corrected to $-45.2^{\circ} \pm 9.1^{\circ}$ (range $-65^{\circ}$ to $-30^{\circ}$ ) at immediate postoperative assessment and $-47.9^{\circ} \pm 7.3^{\circ}$ (range $-67^{\circ}$ to $-40^{\circ}$ ) at the final follow-up (Table 3 ). 
Table 2 Changes in the Cobb angle of thoracic kyphosis

\begin{tabular}{|c|c|c|c|c|c|}
\hline Case & Preop. $\left(^{\circ}\right)$ & After first distracion $\left({ }^{\circ}\right)$ & After second distracion $\left(^{\circ}\right)$ & Postop. $\left({ }^{\circ}\right)$ & Final follow-up $\left(^{\circ}\right)$ \\
\hline 1 & 60 & 41 & Not applicable & 29 & 27 \\
\hline 2 & 90 & 51 & Not applicable & 41 & 43 \\
\hline 3 & 115 & 57 & 61 & 36 & 40 \\
\hline 4 & 64 & 35 & 29 & 38 & 38 \\
\hline 5 & 108 & 47 & 70 & 64 & 49 \\
\hline 6 & 78 & 38 & 33 & 38 & 40 \\
\hline 7 & 90 & 57 & 54 & 45 & 48 \\
\hline 8 & 71 & 43 & Not applicable & 38 & 40 \\
\hline 9 & 60 & 40 & Not applicable & 30 & 30 \\
\hline 10 & 88 & 55 & 54 & 47 & 44 \\
\hline 11 & 86 & 59 & Not applicable & 42 & 44 \\
\hline 12 & 88 & 53 & Not applicable & 36 & 38 \\
\hline 13 & 85 & 21 & 31 & 25 & 28 \\
\hline 14 & 60 & 43 & Not applicable & 22 & 20 \\
\hline 15 & 95 & 65 & 52 & 30 & 31 \\
\hline 16 & 84 & 42 & Not applicable & 37 & 37 \\
\hline 17 & 97 & 50 & 48 & 36 & 40 \\
\hline Average & 83.5 & 46.9 & $49(n=9)$ & 37.3 & 37.5 \\
\hline
\end{tabular}

Table 3 Radiographic data of patients

\begin{tabular}{|c|c|c|c|c|c|c|}
\hline & Preop. (range) & IMPO (range) & $\begin{array}{l}\text { IM corr. } \\
(\%)\end{array}$ & Final follow-up (range) & $\begin{array}{l}\text { Final corr. } \\
(\%)\end{array}$ & $\begin{array}{l}\text { LOC } \\
(\%)\end{array}$ \\
\hline \multicolumn{7}{|c|}{ Proximal thoracic curve } \\
\hline Magnitude $\left(^{\circ}\right)$ & $56.7 \pm 17.3(27-83)$ & $24.1 \pm 13.5(3-51)$ & 60.1 & $25.5 \pm 13.1(4-53)$ & 57.1 & 3.0 \\
\hline Flexibility (\%) & $26.8 \pm 15.1(1.4-45.8)$ & & & & & \\
\hline \multicolumn{7}{|c|}{ Main thoracic curve } \\
\hline Magnitude $\left({ }^{\circ}\right)$ & $110.1 \pm 16.8(92-145)$ & $31.8 \pm 14.3(10-60)$ & 72.4 & $33.5 \pm 13.9(12-63)$ & 70.3 & 2.1 \\
\hline Flexibility (\%) & $10.8 \pm 7.3(0.8-25)$ & & & & & \\
\hline \multicolumn{7}{|c|}{ Thoracolumbar/lumbar curve } \\
\hline Magnitude $\left({ }^{\circ}\right)$ & $48.6 \pm 15.4(25-90)$ & $13.6 \pm 11.9(2-50)$ & 75.1 & $13.4 \pm 10.3(1-44)$ & 74.8 & 0.3 \\
\hline Flexibility (\%) & $41.2 \pm 22.9(8-86.2)$ & & & & & \\
\hline $\begin{array}{l}\text { Coronal } \\
\text { imbalance } \\
(\mathrm{cm})\end{array}$ & $0.5 \pm 0.3(0-2.1)$ & $0.5 \pm 0.2(0-1.6)$ & & $0.4 \pm 0.2(0-1.5)$ & & \\
\hline $\begin{array}{l}\text { Sagittal } \\
\text { imbalance } \\
(\mathrm{cm})\end{array}$ & $-0.5 \pm 1.0(-3.2$ to 2.6$)$ & $-0.5 \pm 0.8(-2.1$ to 2.4$)$ & & $-0.4 \pm 0.6(-2.0$ to 2.4$)$ & & \\
\hline $\begin{array}{l}\mathrm{T} 12-\mathrm{S} 1 \text { lordosis } \\
\left({ }^{\circ}\right)\end{array}$ & $-69.6 \pm 17.8(-102$ to -39$)$ & $-45.2 \pm 9.1(-65$ to -30$)$ & & $-47.9 \pm 7.3(-67$ to -40$)$ & & \\
\hline
\end{tabular}

Final corr correction rate of final follow-up, IM corr immediate postoperative correction rate, IMPO immediate postoperative, $L O C$ loss of correction, Preop preoperative

The first internal distraction corrected the mean Cobb angle of the major curve in the coronal plane by a mean of $49.7 \%$ (from $110.1^{\circ}$ to $55.8^{\circ}$ ), and in nine patients who underwent two distraction procedures, the second distraction corrected it by an additional $5.4 \%$ compared with the initial curve magnitude (from $57.6^{\circ}$ to $47.8^{\circ}$ ). After arthrodesis, the mean correction of the major curve was $72.4 \%$ (from $110.1^{\circ}$ to $31.8^{\circ}$ ) (range 50.8-89.2\%) (Table 3; Fig. 1a-f). At the final follow-up, the mean correction of the major curve was $70.3 \%$ (range 
55.1-87.1\%). At the most recent follow-up, the correction rate of proximal thoracic curve and thoracolumbar or lumbar curve was 57.1 and $74.8 \%$, respectively (Table 3).

The preoperative coronal imbalance of $0.5 \mathrm{~cm}$ (range $0-2.1$ ) was improved to $0.4 \mathrm{~cm}$ (range $0-1.5$ ) at the final follow-up. The preoperative sagittal imbalance of $-0.5 \mathrm{~cm}$ (range -3.2 to 2.6 ) was improved to $-0.4 \mathrm{~cm}$ (range -2.0 to 2.4) at the final follow-up (Table 3).

Mean operating time of the first surgery, second distraction, and final procedure was $278.8 \pm 31.3$, $39.5 \pm 7.3$, and $315 \pm 36.8 \mathrm{~min}$, respectively, with a blood loss of $1492.1 \pm 406.7 \mathrm{ml}$ (Table 4). No patient received blood transfusion during the perioperative period of the first and second distraction surgery. Nine patients received blood transfusion during or after the final fusion surgery with an average of $755.6 \pm 255.5 \mathrm{ml}$. There was no patient required intensive care unit support after surgery during the hospital stay. Average hospital stay was $36.9 \pm 9.1$ days. Transient dyspnoea occurred in one patient after the initial surgery and subsequently resolved. No ventilator support was needed. Three patients complained the pain of concave soft tissue after the first distraction. There were no neurological complications or any deep wound infections. No complication of instrumentation was found at final follow-up (Table 4).

\section{Discussion}

Kyphoscoliosis brings more difficulty for surgeon than scoliosis, especially in patients with severe deformity, because it means greater difficulty of pedicle screw implantation, and often needs aggressive osteotomy to correct sagittal kyphosis. Various kinds of correction method, which usually include three-column osteotomy, have been developed to treat such kind of patients [1-20]. Vertebral column resection (VCR), which enables translation of spinal column and offers the advantage of a controlled manipulation of both the anterior and posterior column, is the most popular technique designed for severe kyphoscoliosis deformities [1-16]. Modi et al. [17] applied posterior multilevel vertebral osteotomy to treat severe kyphoscoliosis, and satisfactory clinical and radiologic results were achieved. In addition, eggshell osteotomy [19], vertebral decancellation [5], and multilevel-modified VCR [20] are also used to treat severe kyphoscoliosis. Although with satisfactory correction of deformity, such aggressive osteotomies are accompanied by high risk of complications or excessive blood loss. For example, VCR has the rate of neurological complications or intraoperative neurological events from 6.3 to $27 \%$ [1-16]. In the report about posterior multilevel vertebral osteotomy, average blood loss was $3015 \pm 1213 \mathrm{ml}$ [17].

Table 4 Demographics and surgical data of patients

\begin{tabular}{|c|c|c|c|c|c|c|c|}
\hline \multirow[t]{2}{*}{ Case } & \multicolumn{3}{|c|}{ Op. time (min) } & \multirow[t]{2}{*}{ Blood loss (ml) } & \multirow[t]{2}{*}{ Blood transfusion (ml) } & \multirow[t]{2}{*}{ Hospital stay (days) } & \multirow[t]{2}{*}{ Complications } \\
\hline & $\begin{array}{l}\text { First } \\
\text { surgery }\end{array}$ & $\begin{array}{l}\text { Second } \\
\text { surgery }\end{array}$ & $\begin{array}{l}\text { Fusion } \\
\text { surgery }\end{array}$ & & & & \\
\hline 1 & 260 & Not applicable & 255 & 1050 & - & 30 & None \\
\hline 2 & 260 & Not applicable & 315 & 900 & - & 34 & None \\
\hline 3 & 340 & 40 & 375 & 1750 & 800 & 35 & None \\
\hline 4 & 290 & 30 & 340 & 1830 & 1000 & 35 & None \\
\hline 5 & 275 & 50 & 285 & 2200 & - & 41 & CSP \\
\hline 6 & 255 & 40 & 325 & 1205 & - & 50 & None \\
\hline 7 & 240 & 50 & 390 & 1630 & 600 & 43 & CSP \\
\hline 8 & 240 & Not applicable & 300 & 1700 & - & 27 & None \\
\hline 9 & 260 & Not applicable & 310 & 1600 & - & 31 & None \\
\hline 10 & 310 & 40 & 355 & 2300 & 1200 & 47 & None \\
\hline 11 & 335 & Not applicable & 280 & 1500 & - & 26 & CSP \\
\hline 12 & 240 & Not applicable & 285 & 800 & 300 & 28 & None \\
\hline 13 & 295 & 30 & 275 & 1600 & 600 & 40 & None \\
\hline 14 & 260 & Not applicable & 310 & 1300 & 700 & 29 & None \\
\hline 15 & 285 & 35 & 350 & 1300 & 800 & 57 & $\begin{array}{r}\text { Transient } \\
\text { dyspnea }\end{array}$ \\
\hline 16 & 305 & Not applicable & 295 & 1300 & - & 30 & None \\
\hline 17 & 290 & 40 & 310 & 1400 & 800 & 52 & CSP \\
\hline Average & 278.8 & $39.5(n=9)$ & 315 & 1492.1 & $755.6(n=9)$ & 36.9 & \\
\hline
\end{tabular}

CSP concave soft-tissue pain after the first distraction 
Compared with above aggressive osteotomies, our correction method, which includes staged anterior release, posterior internal distraction and subsequent posterior spinal fusion, has a number of advantages as follow:

1. It is much safer. Our correction method obviates threecolumn osteotomy. The flexibility of spine is increased by adequate release, but the vertebrae are still connected by the remaining ligaments and annulus, so the possibility of subluxation during surgery is low. Thoracic kyphosis is greatly corrected before the final fusion surgery. There is no need to shorten the posterior column aggressively to correct kyphosis, so the risk of spinal cord overshortening is quite low. There were no neurological complications or an intraoperative neurological event in this series of patients.

2. It is simpler. Anterior release and posterior internal distraction are not highly technical procedures, but they can correct both scoliosis and kyphosis greatly. In the final fusion surgery, the implantation of pedicle screws becomes easier and the correction of residue deformity is not too difficult. This means less operating time and blood loss. The operating time and blood loss of fusion surgery averaged $315 \pm 36.8 \mathrm{~min}$ and $1111.8 \pm 390.3 \mathrm{ml}$, respectively, which was much less than above aggressive surgeries.

3. The surgeries were performed in two or three stages, and the time of every surgery was not very long. So the patients had time to recover and were more tolerant of this correction method. No patient received blood transfusion during the perioperative period of the first and second distraction surgery. Only nine patients received blood transfusion during or after the final fusion surgery, and no patient required intensive care unit support.

Compared with VCR or posterior multilevel vertebral osteotomy, we had achieved similar or even better deformity correction. Lenke et al. published their results of VCR for severe kyphoscoliosis. A $55 \%$ scoliosis correction was achieved, and the preoperative sagittal kyphosis of $104^{\circ}$ was corrected to $45^{\circ}$ [9]. Modi et al. [17] applied posterior multilevel vertebral osteotomy to treat severe kyphoscoliosis. A $54.3 \%$ scoliosis correction was achieved, and the preoperative sagittal kyphosis of $73.6^{\circ}$ was corrected to $45.3^{\circ}$. In this study, the preoperative main thoracic curve of $110.1^{\circ}$ was corrected to $33.5^{\circ}$ at the most recent follow-up assessment, showing a $70.3 \%$ scoliosis correction. The preoperative sagittal kyphosis of $83.5^{\circ}$ was corrected to $37.5^{\circ}$.

After anterior release and first distraction, the preoperative thoracic kyphosis of $83.5^{\circ} \pm 16.3^{\circ}$ was corrected to $46.9^{\circ} \pm 10.7^{\circ}$, which was close to normal range. It is quite easy to correct the thoracic kyphosis by anterior release and posterior internal distraction. Anterior release dramatically increases the flexibility of the spine. When the distraction rod bent to the normal sagittal contour is connected to the pedicle screws, the thoracic kyphosis was partially corrected. Then the proximal and distal pedicle screw caps are locked, and distraction is performed between Domino Connector and rod holder. The spinal column would be lengthened and vertebrae will realign along the rod, especially the vertebrae around the apex, whose flexibility is dramatically increased by anterior release. By such kind of mechanism, the thoracic kyphosis is corrected to almost normal range. However, the spinal column can not be lengthened without limitation. When the spinal column is lengthened to some degree, its stiffness will exceed the rod. If more distraction was performed, the rod will bent. So in some patients, second distraction increased the thoracic kyphosis.

When it comes to indication, we want to emphasize that this method is more suitable for the patients with global kyphosis, not angular kyphosis. In the patients with severe kyphoscoliosis, the spine column rotates greatly and is close to chest wall, so it is easy to perform anterior release. However, severe scoliosis is rare in the patients with angular kyphosis. So in anterior surgery, the angular deformity is deep and it is hard to do anterior release. In addition, it is dangerous to do distraction without resection of angular bone which causes spinal cord compression.

This correction method is a good option for severe kyphoscoliosis, but some disadvantages should be mentioned. First, pulmonary function will be compromised because of anterior surgery. In this study, transient dyspnea occurred in one patient after anterior surgery; however, fortunately, it subsequently resolved and no ventilator support was needed. Second, staged surgeries mean longer hospital stay time and more anesthetic times. Third, repeated surgeries may increase the rate of infection. Fortunately, there is no infection in this series of patients, but it can never be stressed enough that great care should be excised to avoid infection.

Conflict of interest None declared.

\section{References}

1. Leatherman KD (1973) The management of rigid spinal curves. Clin Orthop Relat Res 93:215-224

2. Bradford DS, Tribus CB (1997) Vertebral column resection for the treatment of rigid coronal decompensation. Spine (Phila Pa 1976) 22:1590-1599

3. Zhou C, Liu L, Song Y, Liu H, Li T, Gong Q, Zeng J, Kong Q (2011) Anterior and posterior vertebral column resection for 
severe and rigid idiopathic scoliosis. Eur Spine J 20:1728-1734. doi:10.1007/s00586-011-1861-z

4. Ren C, Liu L, Song Y, Zhou C, Liu H, Li T (2014) Comparison of anterior and posterior vertebral column resection versus anterior release with posterior internal distraction for severe and rigid scoliosis. Eur Spine J 23:1237-1243. doi:10.1007/s00586-0143270-63

5. Tokunaga M, Minami S, Kitahara H, Isobe K, Nakata Y, Moriya H (2000) Vertebral decancellation for severe scoliosis. Spine (Phila Pa 1976) 25:469-474

6. Suk SI, Kim JH, Kim WJ, Lee SM, Chung ER, Nah KH (2002) Posterior vertebral column resection for severe spinal deformities. Spine (Phila Pa 1976) 27:2374-2382. doi:10.1097/01.BRS. 0000032026.72156.1D

7. Suk SI, Chung ER, Kim JH, Kim SS, Lee JS, Choi WK (2005) Posterior vertebral column resection for severe rigid scoliosis. Spine (Phila Pa 1976) 30:1682-1687

9. Lenke LG, Sides BA, Koester LA, Hensley M, Blanke KM (2010) Vertebral column resection for the treatment of severe spinal deformity. Clin Orthop Relat Res 468:687-699. doi:10. 1007/s11999-009-1037-x

10. Lenke LG, Newton PO, Sucato DJ, Shufflebarger HL, Emans JB, Sponseller PD, Shah SA, Sides BA, Blanke KM (2013) Complications after 147 consecutive vertebral column resections for severe pediatric spinal deformity: a multicenter analysis. Spine (Phila Pa 1976) 38:119-132. doi:10.1097/BRS. 0b013e318269fab1

11. Sponseller PD, Jain A, Lenke LG, Shah SA, Sucato DJ, Emans JB, Newton PO (2012) Vertebral column resection in children with neuromuscular spine deformity. Spine (Phila Pa 1976) 37:E655-E661. doi:10.1097/BRS.0b013e318244460d

12. Smith JS, Wang VY, Ames CP (2008) Vertebral column resection for rigid spinal deformity. Neurosurgery 63:177-182. doi:10. 1227/01.NEU.0000320429.32113.85

13. Hamzaoglu A, Alanay A, Ozturk C, Sarier M, Karadereler S, Ganiyusufoglu K (2011) Posterior vertebral column resection in severe spinal deformities: a total of 102 cases. Spine (Phila Pa 1976) 36:E340-344. doi:10.1097/BRS.0b013e3182015712

14. Xie J, Wang Y, Zhao Z, Zhang Y, Si Y, Yang Z, Liu L, Lu N (2011) One-stage and posterior approach for correction of moderate to severe scoliosis in adolescents associated with Chiari I malformation: is a prior suboccipital decompression always necessary? Eur Spine J 20:1106-1113. doi:10.1007/s00586-011$1717-6$

15. Xie J, Wang Y, Zhao Z, Zhang Y, Si Y, Li T, Yang Z, Liu L (2012) Posterior vertebral column resection for correction of rigid spinal deformity curves greater than 100 degrees. J Neurosurg Spine 17:540-551. doi:10.3171/2012.9.SPINE11102611

16. Xie JM, Zhang Y, Wang YS, Bi N, Zhao Z, Li T, Yang H (2014) The risk factors of neurologic deficits of one-stage posterior vertebral column resection for patients with severe and rigid spinal deformities. Eur Spine J 23:149-156. doi:10.1007/s00586013-2793-6

17. Modi HN, Suh SW, Hong JY, Yang JH (2011) Posterior multilevel vertebral osteotomy for severe and rigid idiopathic and nonidiopathic kyphoscoliosis: a further experience with minimum two-year follow-up. Spine (Phila Pa 1976) 36:1146-1153. doi:10. 1097/BRS.0b013e3181f39d9b

18. Suh SW, Modi HN, Yang J, Song HR, Jang KM (2009) Posterior multilevel vertebral osteotomy for correction of severe and rigid neuromuscular scoliosis: a preliminary study. Spine (Phila Pa 1976) 34:1315-1320. doi:10.1097/BRS.0b013e3181a028bc

19. Mikles MR, Graziano GP, Hensinger aR (2001) Transpedicular eggshell osteotomies for congenital scoliosis using frameless stereotactic guidance. Spine (Phila Pa 1976) 26:2289-2296

20. Wang Y, Zhang Y, Zhang X, Huang P, Xiao S, Wang Z, Liu Z, Liu B, Lu N, Mao K (2008) A single posterior approach for multilevel modified vertebral column resection in adults with severe rigid congenital kyphoscoliosis: a retrospective study of 13 cases. Eur Spine J 17:361-372. doi:10.1007/s00586-007-0566-9

21. Zhou C, Liu L, Song Y, Liu H, Li T, Gong Q, Zeng J, Kong Q (2013) Anterior release internal distraction and posterior spinal fusion for severe and rigid scoliosis. Spine (Phila Pa 1976) 38:E1411-1417. doi:10.1097/BRS.0b013e3182a3cd90

22. Buchowski JM, Bhatnagar R, Skaggs DL, Sponseller PD (2006) Temporary internal distraction as an aid to correction of severe scoliosis. J Bone Joint Surg Am 88:2035-2041. doi:10.2106/ JBJS.E.00823 